\title{
Beyond the Individual: Toward a Nomological Network of Organizational Empowerment
}

\author{
N. Andrew Peterson ${ }^{1,3}$ and Marc A. Zimmerman ${ }^{2}$
}

\begin{abstract}
Empowerment research has generally been limited to the individual level of analysis. Efforts to study empowerment beyond the individual require conceptual frameworks suggesting attributes that define the construct and guide its measurement. This paper presents an initial attempt to describe the nomological network of empowerment at the organizational level of analysis - organizational empowerment (OE). Intraorganizational, interorganizational, and extraorganizational components of $\mathrm{OE}$ are described. Implications for empowerment theory and practice are discussed.
\end{abstract}

KEY WORDS: empowerment theory; measurement; empowered organizations.

Empowerment is an active, participatory process through which individuals, organizations, and communities gain greater control, efficacy, and social justice (Rappaport, 1987; Solomon, 1976). It has been promoted as a principal theory of community psychology (Rappaport, 1981, 1984, 1987), identified as a major goal of health promotion (Braithwaite \& Lythcott, 1989; Breslow, 1992) and social work (Itzhaky \& York, 2002; Pinderhughes, 1989), and used as a guide for intervention in high-risk communities (Bentley, 2000; Minkler, Thompson, Bell, \& Rose, 2001). Scholarly interest in empowerment theory is rooted in the recognition that effective social movements and interventions require empowerment-related processes and outcomes across multiple levels of analysis (Perkins \& Zimmerman, 1995).

Although empowerment may be considered multilevel in nature, most empirical work has been limited to the individual level (Zimmerman, 2000).

\footnotetext{
${ }^{1}$ Department of Community and Behavioral Health, College of Public Health, University of Iowa, Iowa City, Iowa.

${ }^{2}$ Department of Health Behavior \& Health Education, School of Public Health, University of Michigan, Ann Arbor, Michigan.

${ }^{3}$ To whom correspondence should be addressed at Department of Community and Behavioral Health, College of Public Health, University of Iowa, 200 Hawkins Drive, E238 GH, Iowa City, Iowa 52242; e-mail: andrew-peterson@uiowa.edu.
}

Studies have focused on participatory mechanisms (Cox, 2002; Gutiérrez, 1995; Le Bosse et al., 1999; Peterson \& Reid, 2003) and measurement (Frymier, Shulman, \& Houser, 1996; Segal, Silverman, \& Temkin, 1995; Speer, 2000; Speer \& Peterson, 2000; Spreitzer, 1995; Zimmerman, 1995; Zimmerman \& Zahniser, 1991) of individual-level empowerment rather than relevant processes, structures, and outcomes for organizations and communities.

Research on empowerment at the organizational level-organizational empowerment (OE) -is particularly needed (Bartle, Couchonnal, Canda, \& Staker, 2002; Boyd \& Angelique, 2002; Gutiérrez, GlenMaye, \& DeLois, 1995; Klein, Ralls, Smith-Major, \& Douglas, 2000; Zimmerman, 2000). Zimmerman (2000) noted that a focus on OE would assist in moving empowerment theory beyond individual bias, that is, the tendency to reduce complex person-in-environment phenomena to individual dynamics, which has dominated fields such as psychology (Sampson, 1977) and social work (Specht \& Courtney, 1994). This individual bias, in turn, may unwittingly blame individuals and result in interventions that focus solely on individual behavior change. Katz and Kahn (1978) also suggested that such an individual bias for interventions is founded upon psychological fallacies whereby individuals are solely responsible for their 
outcomes without attention to environmental and contextual issues. In addition, a focus on OE would help reconcile the sometimes erroneous conclusion that empowerment theory favors traditionally individualistic and conflict-oriented values (Riger, 1993) by incorporating collective principles needed to describe empowerment in organizational contexts (Rappaport, 1995). Empirical studies on OE will require conceptual frameworks suggesting attributes that define the construct, guide its measurement, and yield practical strategies and tactics. This paper focuses on development of a conceptual model of OE. Zimmerman (2000) has identified components of empowerment across levels of analysis-notions of control, understanding social systems, and participation-but that analysis did not focus on OE.

The central goal of this paper is to present a nomological network of OE. A nomological network is a theoretical framework that represents the basic features of a construct, their observable manifestations, and the interrelationships among them (Cronbach \& Meehl, 1955). Articulating a nomological network of OE has important implications for future research and practice because it enables subsequent development of new measures, measurement models, and OE-guided interventions. Concrete operations of OE, for example, could be developed for community-based organizations engaged in substance abuse prevention. Researchers could then test the validity of OE by empirically examining its relationship with goal achievement (e.g., reduced substance abuse in a target community). Creating ways to assess and validate $\mathrm{OE}$ concepts are essential for designing corresponding interventions focused at the organizational level. The first step, however, in measuring and validating $\mathrm{OE}$ is to describe its nomological network. This paper is organized in the following way. OE is defined and empowerment literature is reviewed to provide a rationale for our focus on organizational-level features that characterize empowered organizations. Intraorganizational, interorganizational, and extraorganizational qualities of empowered organizations are identified and integrated into a nomological network. Critical analysis of the framework is then provided. Implications of the model for future research and practice are also discussed.

\section{DEFINING ORGANIZATIONAL EMPOWERMENT}

Zimmerman's (2000) theoretical framework provides a basis for defining OE and its interdepen- dence with empowerment at individual and community levels of analysis. Empowerment at the individual level may be labeled psychological empowerment (PE). Zimmerman (1995) proposed one way to conceptualize PE as intrapersonal, interactional, and behavioral components. At the organizational level, OE refers to organizational efforts that generate $\mathrm{PE}$ among members and organizational effectiveness needed for goal achievement. Empowerment at the community level of analysis-community empowerment-includes efforts to deter community threats, improve quality of life, and facilitate citizen participation. This framework is useful because it extends empowerment theory and asserts that there are specific processes and outcomes across levels of analysis, and that these need to be developed in more detail to delineate a nomological network for OE.

To date, empowerment theorists have not developed a clear and coherent nomological network for OE that articulates a clear differentiation from PE. Although the term appears in the empowerment literature, $\mathrm{OE}$ is often defined as individual empowerment derived within organizational contexts (Hardiman \& Segal, 2003; Segal et al., 1995). This conceptualization, however, fails to incorporate organizational-level constructs that are separate and distinct from individual members. Segal et al. (1995), for instance, presented a validation study of $\mathrm{OE}$, but their conceptualization and assessment was limited to individual level "member participation in formal spheres, e.g., the self-help organization, and community political action" (p. 224). This predominant focus on the individual may be why some researchers (e.g., Rissel, 1994) caution against empowerment as a major goal of intervention due to the lack of a clear theoretical underpinning beyond the individual.

In an attempt to address this issue, Gerschick, Israel, and Checkoway (1990), Swift and Levin (1987), and Zimmerman (2000) made an important conceptual distinction between empowering and empowered organizations. They described empowering organizations as those that produce PE for individual members as part of their organizational process, while empowered organizations were described as those that influence the larger system of which they are a part. These notions parallel concepts offered by organizational theorists such as Jacoby and Babchuk (1963) and Rose (1954) who described expressive (i.e., focus on expressing or satisfying member interests) and instrumental (i.e., focus on achieving a condition or change in society) organizations. These ideas are applicable to OE because they underscore 
differences between what organizations achieve internally for members and what they achieve externally for communities.

Efforts have been made to move toward a focus on identifying organizational characteristics of empowering organizations (e.g., Foster-Fishman \& Keys, 1997; Foster-Fishman, Salem, Chibnall, Legler, \& Yapchai, 1998; Gutiérrez et al., 1995; Maton \& Salem, 1995; Matthews, Diaz, \& Cole, 2003). Gutiérrez et al. (1995) conducted a qualitative study of 27 human services organizations engaged in empowerment practice. They found that organizational characteristics such as administrative leadership and support were important for agencies to maintain an atmosphere of empowerment. Elsewhere, Matthews et al. (2003) developed a scale to assess perceptions of three characteristics of work environments that were hypothesized to affect employees' PE. This included the company's provision of modifiable guidelines that assisted employee decision making, a climate that facilitated input of employees into decisions concerning all aspects of their professional careers, and procedures that made information about a company accessible to all of its employees. Matthews et al. (2003) labeled their measure an OE scale, but they restricted their focus to organizational characteristics that facilitated employee PE rather than variables that characterized companies that were empowered.

In other studies, Maton and Salem (1995) used an inductive process to synthesize findings from three case studies that identified organizational characteristics of community settings that appeared to generate member PE. They observed that a strength-based culture of growth, a role structure that afforded members opportunities for multiple and meaningful roles, leadership that was shared, inspiring and organizationally talented, and an encompassing, peer-based support system were vital aspects of an empowering organization (i.e., help to enhance member PE). Foster-Fishman and Keys (1997) applied an organizational culture framework in a case study of a public bureaucracy that developed an empowerment program for employees. They described the ways that subcultures of local sites affected the extent to which an organization might be empowering for its employees. Foster-Fishman et al. (1998) extended this work to further elaborate how empowerment took on different meanings across people and the ways that characteristics of different social environments influenced $\mathrm{PE}$.

These studies encourage further development of conceptual models that explicitly include organizational-level attributes that define OE. Yet, most of the focus of this work is on the characteristics of organizations that make them empowering for their members. Less studied, and less conceptually developed, are those characteristics of organizations that indicate their level of empowerment. One goal of this paper is to present a model of OE so that we can examine the extent to which organizations are empowered.

We suggest that a conceptual model of empowered organizations includes three components: intraorganizational, interorganizational, and extraorganizational. The intraorganizational component of $\mathrm{OE}$ includes characteristics that represent the internal structure and functioning of organizations. The intraorganizational component is critical because it provides the infrastructure for members to engage in proactive behaviors necessary for goal achievement. The interorganizational component of $\mathrm{OE}$ includes the linkages between organizations. The interorganizational component is vital because it refers to the relationships and collaboration across organizations. The extraorganizational component of OE refers to actions taken by organizations to affect the larger environments of which they are a part. The extraorganizational component is crucial because it represents organizational or multiorganizational efforts to exert control. Examples of organizational actions that may be relevant include policy change, creating alternative services, or successful advocacy.

A conceptual model of empowered organizations also requires an overarching view of how people and social systems affect each other. The ecological perspective (Kelly, 1966) provides this orientation because it focuses on the interrelationships between individuals and community organizations, organizational-level processes and outcomes within and across organizations, as well as between organizations and the larger environments within which they exist (Kelly, Ryan, Altman, \& Stelzner, 2000; Scott, 1998). The interrelationships involve transactions that unfold in several ways that are relevant for OE. First, organizations provide the mediating structures that help individuals navigate and cope with the larger systems of community life (Berger \& Neuhaus, 1977). These transactions provide opportunities for individual development and give individuals a context to exert influence on larger community systems. The interrelationships of organizational structure and processes that provide opportunities for development (i.e., empowering processes) are vital for individuals to get the most out of organizational 
involvement. Second, the transactions across organizations provide a basis for organizations to enhance their community standing and increase their capability to influence community life. Third, the transactions between organizations and the larger community institutions (e.g., education, government) provide the means by which organizations influence policy or provide an alternative service. An ecological perspective is critical to the development of a theoretical model of OE because it offers an overarching framework that both focuses our attention to levels of analysis beyond the individual (i.e., corrects for individual bias) and provides a lens for examining the confluence of factors that characterize empowered organizations.

Our application of the ecological perspective to OE includes the conceptualization of organizationallevel outcomes as intraorganizational, interorganizational, and extraorganizational components. Outcomes may be referred to as operationalizations, whether quantitative or qualitative, which reflect the efforts of organizations to thrive and be successful at achieving their missions. It also includes the identification of organizational processes that are relevant to OE outcomes. Processes in the context of OE may be considered those that create opportunities for organizations and their members to gain control and achieve individual and shared goals. We include organizational processes because they relate to, and maybe even influence, the level of OE achieved by an organization. Table I presents outcomes that represent empowered organizations and processes that are related to the empowerment characteristics of each component.

\section{COMPONENTS OF ORGANIZATIONAL EMPOWERMENT}

\section{Intraorganizational Component of Organizational Empowerment}

Based on the literature, outcomes that represent intraorganizational empowerment may be said to include variables such as viability (Perkins et al., 1996; Prestby, Wandersman, Florin, Rich, \& Chavis, 1990), underpopulated settings (Zimmerman et al., 1991), collaboration of coempowered subgroups (Bond \& Keys, 1993; Gruber \& Trickett, 1987), resolved ideological conflict (Riger, 1984), and resource identification (Zimmerman et al., 1991). Variables included in this component of $\mathrm{OE}$ are intended to represent the internal structure and functioning of organizations that may be foundational for goal achievement.

Viability may be considered an internal feature that characterizes organizations that are empowered. Prestby et al.'s (1990) study of block associations in New York City described the effects of setting variables on organizational viability. Viability was operationalized in their study as a dichotomous variable that classified organizations as active or inactive. Active organizations had held at least one meeting or one activity during a 6-month period, while inactive organizations held no meetings or activities during this time despite having failed to accomplish goals. They considered viability as a critical organizational-level outcome that represented OE. In a related study, Perkins et al. (1996) further examined block associations using a longitudinal design to explore whether organizational viability was related over time to the physical, economic, and social environments of neighborhood blocks. Their study revealed that the most viable organizations were on neighborhood blocks that had more long-term residents, trees, gardens, and outdoor lighting, and were more likely to be located in minority neighborhoods. In view of these studies, viability may be considered an intraorganizational outcome of OE because it represents a fundamental quality that is indicative of organizations that are functional, provide services, influence communities, and obtain goals.

The presence of underpopulated settings may also be considered an intraorganizational outcome that characterizes empowered organizations. Zimmerman et al. (1991) studied a mutual help organization in Illinois for people experiencing emotional difficulties. They found that the presence of underpopulated settings (Barker, 1960; Barker \& Gump, 1964; Wicker, 1987) was an important organizational feature that contributed to its goal of augmenting existing mental health services across the state. An underpopulated setting is a social milieu, such as a support group within a faith organization or an extracurricular club within a school, which has fewer than the optimal number of persons available to occupy the number of roles. Conversely, overpopulated settings have more than the optimal number of people available to occupy the number of roles. The presence of underpopulated settings may be regarded as an intraorganizational outcome of OE because it represents a structural feature that results from efforts to generate the meaningful involvement of members in organizational functioning. 
Table I. Processes and Outcomes for Intraorganizational, Interorganizational, and Extraorganizational Components of Organizational Empowerment

\begin{tabular}{|c|c|c|}
\hline Component & Processes & Outcomes \\
\hline Intraorganizational & $\begin{array}{l}\text { - Incentive management (Prestby, } \\
\text { Wandersman, Florin, Rich, \& } \\
\text { Chavis, 1990) } \\
\text { - Subgroup linkages (Bond \& Keys, } \\
\text { 1993) } \\
\text { - Opportunity role structure (Maton } \\
\text { \& Salem, 1995; Minkler et al., 2001; } \\
\text { Peterson \& Hughey, 2002; Peterson } \\
\text { \& Speer, 2000; Speer Hughey, } \\
\text { Gersheimer, \& Adams-Lavitt, 1995) } \\
\text { - Leadership (Maton \& Salem, 1995; } \\
\text { Minkler et al., 2001) } \\
\text { - Social support (Gutiérrez et al., } \\
\text { 1995; Kieffer, 1984; Maton, 1988; } \\
\text { Maton \& Salem, 1995; Minkler } \\
\text { et al., 2001; Peterson \& Hughey, } \\
\text { 2002; Peterson \& Speer, 2000) } \\
\text { - Group-based belief system (Maton } \\
\text { \& Salem, 1995; Minkler et al., 2001; } \\
\text { Rappaport, 1993; Spreitzer, 1995) }\end{array}$ & $\begin{array}{l}\text { - Viability (Perkins, Brown \& } \\
\text { Taylor, 1996; Prestby et al., } \\
\text { 1990) } \\
\text { - Underpopulated settings } \\
\text { (Zimmerman et al., 1991) } \\
\text { - Collaboration of coempowered } \\
\text { subgroups (Bond \& Keys, 1993; } \\
\text { Gruber \& Trickett, 1987) } \\
\text { - Resolved ideological conflict } \\
\text { (Riger, 1984) } \\
\text { - Resource identification } \\
\text { (Zimmerman et al., 1991) }\end{array}$ \\
\hline Interorganizational & $\begin{array}{l}\text { - Accessing social networks of other } \\
\text { organizations (Gulati \& Gargiulo, } \\
\text { 1999; Snow, Zurcher, \& } \\
\text { Elkind-Olson, 1980) } \\
\text { - Participating in alliance-building } \\
\text { activities with other organizations } \\
\text { (Foster-Fishman, Salem, Allen, \& } \\
\text { Fahrbach, 2001; Itzhaky \& York, } \\
\text { 2002) }\end{array}$ & $\begin{array}{l}\text { - Collaboration (Bartle et al., } \\
\text { 2002; Baum \& Oliver, 1991; } \\
\text { Checkoway, 1982; Checkoway \& } \\
\text { Doyle, 1980; Orians, Liebow, \& } \\
\text { Branch, 1995) } \\
\text { - Resource procurement } \\
\text { (Zimmerman et al., 1991) }\end{array}$ \\
\hline Extraorganizational & $\begin{array}{l}\text { - Implementing community actions } \\
\text { (Speer et al., 1995; Speer \& Hughey, } \\
\text { 1995) } \\
\text { - Disseminating information (Bonal, } \\
\text { 2000; Burstein, 1999; Stevenson \& } \\
\text { Greenberg, 2000) }\end{array}$ & $\begin{array}{l}\text { - Influence of public policy and } \\
\text { practice (Fawcett et al., 1995; } \\
\text { Speer \& Hughey, 1996) } \\
\text { - Creation of alternative } \\
\text { community programs and } \\
\text { settings (Cherniss \& Deegan, } \\
\text { 2000; Minkler et al., 2001; } \\
\text { Sarason, 1972) } \\
\text { - Deployment of resources in the } \\
\text { community (Zimmerman et al., } \\
\text { 1991) }\end{array}$ \\
\hline
\end{tabular}

Another feature that may be considered an intraorganizational outcome indicative of empowered organizations involves collaboration of coempowered subgroups within the organization (Bond \& Keys, 1993; Gruber \& Trickett, 1987). Bond and Keys (1993) described this quality as an empowerment outcome that may be critical for organizational performance. They noted that in many organizations, several groups may exist with differing motivations, investments, and perspectives that can create tensions that undermine growth and effectiveness. Moreover, the power of these groups to influence organizational agendas, discussions, and decisions may not be equally distributed. Coempowerment was described in their study as different groups each having the capacity to influence decisions and issues affecting the organization. They observed that when organizational subgroups were coempowered and collaborated, a synergy occurred in which the effectiveness of an organization was greater than it would have been had the different groups worked separately and not been coempowered. Similarly, Gruber and Trickett (1987) studied the relationships between subgroups 
of students, parents, and teachers serving on the board of an alternative school. They described how the board began with equal proportions of individuals representing each subgroup and with the intention of facilitating active, meaningful participation. Eventually, however, conflicts between subgroups undermined the involvement of parents and students in decision making and ultimately reduced the effectiveness of the board. These studies show that collaboration of coempowered subgroups is an intraorganizational outcome of OE because it involves an internal quality that reflects the capacity of organizations to take effective action toward shared goals.

Resolved ideological conflict is also a crucial intraorganizational outcome of OE. In her study of feminist-movement organizations, Riger (1984) described the ways that participatory decision-making strategies, which were consistent with the organizations' ideology, were often not the most effective way to ensure organizational survival. She determined that the unresolved conflict that arose between decision-making processes and ideology often threatened the continued existence of these organizations by creating levels of hostility that diminished member loyalty and stifled participant involvement and organizational action. Riger observed that organizational efforts to manage conflict in creative ways may actually stimulate growth and innovations that can benefit organizations. Resolved ideological conflict may be considered an intraorganizational outcome that characterizes empowered organizations because it represents a result of internal activity that may be critical for organizational functioning.

Resource identification, an element of resource mobilization theory (McCarthy \& Zald, 1973, 1977), refers to efforts that identify and develop plans for acquiring the resources needed for organizational sustainability and goal achievement. Resources include people and skills, funding, space, and other material requirements for operation. Zimmerman et al.'s (1991) study applied resource mobilization theory as its conceptual framework to examine strategies used by a mutual help organization to become empowered. They observed that the organization's success was partly due to its completion of an expansion plan. The plan specified the resources the organization would need to achieve goals (e.g., sponsors and funding to open new support centers as well as community presentations and workshops to gain community support). In light of this research, resource identification may be viewed as an intraorganizational outcome of $\mathrm{OE}$ because it represents a state of internal readiness that is indicative of effective organizations.

\section{Intraorganizational Processes}

The empowerment literature provides examples that also help us to clarify understanding of intraorganizational processes related to the empowerment characteristics of this component. Features such as incentive management (Prestby et al., 1990) and subgroup linkages (Bond \& Keys, 1993) may be considered examples of intraorganizational processes of OE because they represent activities that provide opportunities to enhance the structure and functioning of organizations. Incentive management refers to organizational efforts that facilitate member participation by providing incentives and decreasing costs (Prestby et al., 1990). Examples of incentives include opportunities to socialize with neighbors, learn new skills, and gain information. Costs refer to personal expenses incurred as a result of participating in organizations and may include items such as child care and time. In the Prestby et al. (1990) study examining the incentive management of block associations that used strategies of collective action, the researchers found that incentive management promoted perceptions of higher member benefits and greater organizational viability. Incentive management is an intraorganizational process of $\mathrm{OE}$ because it reflects internal functioning that contributes to the supply of membership resources needed for organizations to sustain their activity and exercise their influence in communities.

The organizational feature involving subgroup linkages refers to the process of creating connections between different internal social units of an organization. Bond and Keys' (1993) case study focused on the interrelationships among parent and community member groups participating on the governing board of a support and advocacy organization for people with developmental disabilities. They revealed that linkages serving boundary-spanning functions across groups created an appreciation for collaboration that was important for subgroups to work together to accomplish broader organizational goals. Creating linkages among subgroups may be considered an intraorganizational process of $\mathrm{OE}$ because it represents internal functioning that may enable the cooperation among units within organizations that is vital for goal achievement. 
Internal processes of empowering organizations, such as opportunity role structure (Maton \& Salem, 1995; Minkler et al., 2001; Peterson \& Hughey, 2002; Peterson \& Speer, 2000; Speer et al., 1995), leadership (Maton \& Salem, 1995; Minkler et al., 2001), social support (Gutiérrez et al., 1995; Kieffer, 1984; Maton, 1988; Maton \& Salem, 1995; Minkler et al., 2001; Peterson \& Hughey, 2002; Peterson \& Speer, 2000), and group-based belief system (Maton \& Salem, 1995; Minkler et al., 2001; Rappaport, 1993; Spreitzer, 1995), may also be related to outcomes that characterize empowered organizations. These variables are included in Table I because they represent processes within organizations that set the stage for members to enhance their efficacy, competence, and organizational involvement.

Opportunity role structure includes the amount, accessibility, and arrangement of formal positions or roles within an organization that provide opportunities for members to take control of group tasks and build their skills and competencies (Maton \& Salem, 1995; Speer et al., 1995). Broad opportunity role structure may be considered a process of OE because it represents a feature that encourages members to assume various roles and actively participate in organizational functions. Leadership involves qualities of individuals who are interpersonally and organizationally talented, committed and dedicated to organizations, and support and respond well to group members (Maton \& Salem, 1995; Minkler et al., 2001). Leadership may also represent a process of $\mathrm{OE}$ because it contributes to member participation by providing vision, motivation, and inspiration to organization members. Additionally, an organization's social support system may be considered an OE process. It involves organizational opportunities for members to provide and receive emotional and other resources needed to cope with challenges that may arise from attempts to gain control and achieve goals (Gutiérrez et al., 1995; Kieffer, 1984; Maton, 1988; Maton \& Salem, 1995). Group-based belief system may be regarded as an OE process because it involves the values and culture within an organization that specify desired behaviors and outcomes to guide and sustain goal-directed efforts of organizational members (Maton \& Salem, 1995; Spreitzer, 1995).

\section{Summary and Related Research}

The intraorganizational component of OE refers to the ways organizations are structured and function as members engage in activities that contribute to individual PE and organizational effectiveness needed for goal achievement. Research from other disciplines that is consistent with this focus has sought to develop structural contingency theory in order to identify variables (i.e., degree of bureaucratization) affecting organizational performance (Donaldson, 1995). Other features not studied in the context of empowerment, but that may relate to the intraorganizational component of OE, include the physical design of organizations, information technology (IT), and the existence of by-laws and procedures (Darley \& Gilbert, 1985; Pfeffer, 1997). Features of organizations' physical design, such as lighting, air quality, spatial and architectural arrangements, may be related because they represent qualities of internal environments that may impede or facilitate members' purposive behavior and interactions among them. In addition, the quality of organizations' IT infrastructure may be pertinent to this component because it may frustrate or enhance the ability of members to organize, communicate, control tasks, and effectively act. By-laws and procedures may also be relevant to intraorganizational empowerment because, like resource identification, they may reflect a state of internal readiness that is indicative of effective organizations. The intraorganizational component of OE, which includes features representing the internal structure and functioning of organizations, is part of the assessment of OE achieved by an organization. Intraorganizational empowerment is essential for conceptualizing OE because it provides the foundation for actions necessary to achieve organizational goals.

\section{Interorganizational Component of Organizational Empowerment}

Interorganizational empowerment includes connections and relations between organizations such as collaboration with other organizations (Bartle et al., 2002; Baum \& Oliver, 1991; Checkoway, 1982; Checkoway \& Doyle, 1980; Orians et al., 1995) and resource procurement (Zimmerman et al., 1991). This component of OE is vital because it provides the linkages for organizations to gain resources, share information, attain legitimacy, and accomplish goals.

Collaboration may be considered an interorganizational outcome indicative of empowered organizations. Collaboration refers to cooperative activities such as coordination of services, exchange of information, and formalization of relationships that 
contribute to specific organizational or multiorganizational goals (Alter \& Hage, 1993; Gray, 1985). Several studies suggest that collaboration may characterize empowered organizations. Bartle et al. (2002) conducted a 7-year ethnographic study of a comprehensive child development organization that focused on changing community conditions threatening the economic and social self-sufficiency of families living in poverty. They described the organization's effort to generate more than 100 interagency agreements and informal arrangements with other organizations to address issues such as day care, housing, and transportation. These linkages were critical to the achievement of goals for healthy child development and overall family well-being. Baum and Oliver (1991) studied collaboration of more than 1,000 child care organizations in Canada over a 15 -year period. They reported that organizations with more linkages to other organizations, such as site sharing agreements that provided permission to offer services within the physical facilities of another organization, were more likely to thrive as competition increased in their communities. They described these linkages as providing organizations with the legitimacy, validation, and support needed to effectively provide services in their communities.

Checkoway (1982) and Checkoway and Doyle (1980) described the collaborative efforts of an advocacy organization created by health care consumers to shape policy of a county health planning board in Illinois. The organization was created after an investigation revealed a lack of effective public participation in health care planning. One of the qualities the authors emphasized as crucial for successful organizing efforts was its organizational alliances. These alliances provided a means for technical assistance, encouragement, and the legitimacy needed to effectively challenge public policy. Orians et al. (1995) also examined collaboration among organizations conducting HIV prevention activities in Seattle. They described joint ventures in interagency volunteerism and referrals that were important for organizations to be effective in their prevention initiatives. These studies demonstrate that collaboration may be considered an interorganizational characteristic of an empowered organization because it represents a consequence of efforts to establish connections outside the organization.

Resource procurement is another element of resource mobilization theory (McCarthy \& Zald, 1973, 1977) that is applicable to the interorganizational component of OE. Resource procurement refers to the acquisition of revenues, people, facilities, materials, products, or other resources from other organizations or systems that contribute to organizational effectiveness. Zimmerman et al.'s (1991) study of a mutual help organization described the importance of resource procurement in its efforts to supplement traditional mental health services. The organization established connections with the state mental health system to secure additional funding for expansion of support groups in rural areas. State funds allowed new fieldworkers to be hired, provided for rental space, and covered the administrative costs incurred from efforts to serve more remote regions of the state. Resource procurement may be regarded as an interorganizational outcome of $\mathrm{OE}$ because it represents a result of efforts to connect with and obtain resources from other organizations.

\section{Interorganizational Processes}

The literature also provides examples of interorganizational processes, such as accessing social networks of other organizations (Gulati \& Gargiulo, 1999; Snow et al., 1980) and participating in alliancebuilding activities with other organizations (FosterFishman 2001; Itzhaky \& York, 2002), which are relevant to this component of empowerment. Snow et al. (1980) examined strategies used by social movement organizations to mobilize support for their causes. They asserted that organizations that accessed the social networks of other organizations were found to grow faster than more isolated organizations. Similarly, Gulati and Gargiulo (1999) described concepts of structural and relational embeddedness, which referred to the efforts of organizations to network with other agencies. They found that accessing the social networks of other organizations was crucial to the establishment of collaborative arrangements needed for organizations to influence their environment. Efforts to access the social networks of other organizations may be considered an interorganizational process because it represents activity intended to establish the links with other organizations that may result in collaborative arrangements that facilitate their goal attainment.

Participating in alliance-building activities with other organizations is another example of an interorganizational process related to OE. FosterFishman et al. (2001) used social network analysis 
in a cross-sectional study of 32 organizations in Michigan to determine if participating in a county-wide coordinating council and interagency team was associated with greater interorganizational collaboration. They found that organizations involved in the coordinating council were more likely to be included in administrative and service delivery exchanges with other organizations in their county, while those involved in the interagency team were found to exchange clients and share information with a larger and broader service delivery network than nonparticipating organizations. Their data suggested that these activities played a vital role in facilitating interorganizational collaboration. In another study, Itzhaky and York (2002) reported evaluation findings of a 6-year, community organizing project in Israel that was conducted in an isolated, deprived community comprised mostly second- and third-generation immigrants from Africa, Asia, and the former Soviet Union. One of the goals of the project was to promote collaboration among human service agencies through a workshop training program for human services workers. A key topic of the training was the process of participating in community-wide planning committees and task forces. Organizational participation in these initiatives was considered critical to the development of collaborative efforts needed for improved service delivery. On the basis of these studies, participating in alliance-building activities with other organizations may be viewed as an interorganizational process of $\mathrm{OE}$ because it represents a focused attempt to create connections with other organizations.

\section{Summary and Related Research}

The interorganizational component of OE refers to relationships between organizations. Related research has used boundary-spanning (Katz \& Kahn, 1978; Robertson, 1995) and embedded intergroup relations (Alderfer, 1998) to describe connections between organizations. Critical theory has also been used to examine organizational linkages that are maintained to serve class interests that transcend organizational boundaries (Palmer, 1983; Pfeffer, 1997). The interorganizational component of OE includes variables that represent the linkages between organizations that may be critical for organizations to marshal resources, provide and receive information, and realize objectives.

\section{Extraorganizational Component of Organizational Empowerment}

The extraorganizational component of our model includes the influence of public policy and practice (Fawcett et al., 1995; Speer \& Hughey, 1996), creation of alternative community programs and settings (Cherniss \& Deegan, 2000; Minkler et al., 2001; Sarason, 1972), and deployment of organizational resources in the community (Zimmerman et al., 1991). This component of OE refers to efforts taken by organizations to shape the broader systems of which they are a part. Extraorganizational empowerment, in essence, represents organizational or multiorganizational actions to exert control.

The influence of public policy and practice may be considered a crucial extraorganizational outcome that characterizes empowered organizations. Speer and Hughey (1996) described a community organizing initiative in Kansas City that influenced policies of a city council. The organization in their study was focused at the time on questioning the city's decision to fund an expansion of a convention center instead of interventions to address the community's substance abuse problem. Speer and Hughey applied Gaventa's (1980) framework to describe the ways the organization exercised social power. They described the ability of the organization to reward and punish institutional targets, influence agendas, and shape ideologies-variables they considered as empowerment outcomes at the organizational level of analysis. As a result of the organization exercising its social power, the city increased funding for substance abuse treatment and prevention by $\$ 9$ million. Fawcett et al. (1995) described three community partnerships in Kansas that were organizing for the purpose of preventing adolescent substance abuse. One partnership addressed this issue by changing policy of a local radio station to prohibit disc jockey comments glamorizing drinking. The partnership also influenced practices of local faith organizations by facilitating the training of ministers in prevention strategies that were then implemented in local congregations.

The creation of alternative community programs and settings may also represent an extraorganizational outcome that is indicative of organizations that are empowered. Minkler et al. (2001) presented a multisite case study that examined OE among nine federal Healthy Start programs that utilized a catalyst-for-change approach to prevent infant mortality. These programs were based on the premise that communities themselves are usually best suited 
to generate the strategies needed to tackle the causes of problems confronting them. The Healthy Start programs they described relied heavily on resident involvement in consortia that organized and supported the process of women's empowerment. One of the qualities Minkler et al. (2001) identified as being indicative of the empowerment of these consortia was their creation of alternative programs in their communities. The Cleveland site described in their study, for example, addressed the goal of preventing infant mortality by creating new housing partnership programs that helped families to find emergency and long-term affordable housing. Minkler et al. (2001) viewed this accomplishment as an outcome that indicated that the consortium was empowered. Elsewhere, Cherniss and Deegan (2000) and Sarason (1972) described the creation of alternative community settings as an outcome that may result from organizational effort to shape communities. Cherniss and Deegan (2000) noted that this feature may be distinguished from the influence of public policy and practice because it involves the formation of distinctly new programs or settings.

The deployment of an organization's resources in the community may also be considered an extraorganizational outcome indicative of empowered organizations. Resource mobilization theory (McCarthy \& Zald, 1973, 1977) recognizes that resources must first be identified (intraorganizational empowerment) and procured (interorganizational empowerment) before they may be translated into action (extraorganizational empowerment). Building on this perspective, deployment of resources in the context of extraorganizational empowerment refers to the flow of resources away from the organization. It represents a state of readiness in which an organization's resources are actively engaged in a community. Zimmerman et al.'s (1991) study of a mutual help organization described how resource deployment contributed to its goal of expanding mental health services in its state. The organization in their study had achieved a level of community engagement in which fieldworkers were active throughout the state, targeting people in specific community roles within law enforcement, mental health, public welfare, and media. This effort provided a forum for the organization to advocate for its agenda and shape community decisions affecting the provision of mental health services. The organization also helped to modify mental health policy in the state by changing the way contact hours with patients were counted. The organization convinced the state to count mutual-help hours when the fieldworkers attended a meeting. It is noteworthy that the fieldworkers were not trained mental health professionals in the traditional sense. Rather, they were mutual help organization members who had moved up the ranks. The organization also mobilized resources externally to set up mutual help groups in the community as an alternative service to traditional mental health care. This involved securing meeting space, identifying volunteers, and recruiting new members. Taken together, these studies show that the influence of public policy and practice, the creation of alternative programs and settings, and the deployment of organizational resources may each be considered an extraorganizational outcome of $\mathrm{OE}$ because they represent consequences of efforts to affect communities or exert control in ways that may contribute to the accomplishment of organizational goals.

\section{Extraorganizational Processes}

The literature also provides examples that clarify the understanding of extraorganizational processes related to the empowerment characteristics of this component. These include processes such as implementing community actions (Speer et al., 1995; Speer \& Hughey, 1995) and disseminating information (Bonal, 2000; Burstein, 1999; Stevenson \& Greenberg, 2000). These activities are considered extraorganizational processes because they represent efforts by organizations to influence community life.

A community action is a public meeting or event that is held by an organization in an attempt to exercise social power. Speer et al. (1995) presented a case study of neighborhood-based and faith-based organizations that implemented community actions. These community actions provided members the opportunities to bring public attention to specific problems of concern to them. Members invited other community residents to the event, as well as the news media, and then provided testimony, presented research, and publicly challenged community targets, such as elected officials, to change policies and resource allocations that offered solutions to the problems plaguing their families and neighborhoods. Speer and Hughey (1995) further described this activity as an empowerment process at the organizational level of analysis. They discussed their work with the Pacific Institute for Community Organization (PICO), which organized community actions that mobilized as many as 5,000 citizens to address 
issues such as crime, housing, and substance abuse. They described this activity as a critical organizational process that enabled PICO to influence public policy. These studies demonstrate that implementing a community action is an extraorganizational process of OE because it represents an effort to exert control over community policies and practices that may ameliorate conditions challenging organizational members.

Disseminating information may also be considered an extraorganizational process of empowered organizations. Burstein (1999) provides an overview of social movement organization and interest group activities intended to influence public policy. He described efforts to disseminate information to elected officials and public agencies as well as implement public awareness campaigns that had the potential to change public focus and intensity of concern for community issues. Other researchers have described efforts of social movement organizations to disseminate information intended to influence environmental (Stevenson \& Greenberg, 2000) and educational (Bonal, 2000) policies. Disseminating information may also be considered an extraorganizational process of OE because it represents a systematic effort of organizations to influence decision making, policies, and practices of communities.

\section{Summary and Related Research}

The extraorganizational component of $\mathrm{OE}$ refers to actions taken by organizations to affect the larger environments of which they are a part. Researchers from other disciplines have used econometric models to examine business practices, such as lobbying and campaign contributions, used to shape public policies in order to maximize profits (Damania \& Fredriksson, 2000). This focus on organizational influence as foundational for goal achievement is also consistent with Trist's (1986) assertion that diffusion of successful innovations may be accelerated if organizational innovations are linked to a wider process of community change. The extraorganizational component of $\mathrm{OE}$ includes qualities that characterize organizations' efforts to exert influence beyond their boundaries. This component of OE is important because the capacity of organizations to achieve changes in their environments may be considered a critical foundation for attainment of more specific organizational goals.

\section{NOMOLOGICAL NETWORK FOR ORGANIZATIONAL EMPOWERMENT}

In developing a nomological network for PE, Zimmerman (1995) applied a process for construct validation discussed by Cronbach and Meehl (1955). They described a construct as an abstract idea for which the interrelationships among relevant, observable variables have been specified. They discussed the process for validating a construct as starting with articulation of a general framework to represent its basic features-its nomological network. The nomological network we present here conceptualizes outcomes of OE as intraorganizational, interorganizational, and extraorganizational components. These components combine to create a snapshot of organizations that possess characteristics indicative of being empowered. Empowered organizations possess internal features (intraorganizational outcomes), linkages that promote organizational and shared interests (interorganizational outcomes), and actions that influence policy and decision making in the broader community (extraorganizational outcomes).

Cronbach and Meehl (1955) pointed out that once concrete operations for variables in a nomological network are made explicit, the validity of a construct can then be empirically tested. Creating operations, however, requires recognition that empowerment, like other constructs, is open-ended. The variables used to represent the construct may change over time and depend on the specific circumstances in which they are measured. As Zimmerman (1995) noted, components of PE "may not be fully captured by any one specific operationalization because they take on different forms in different populations, contexts, and times" (p. 587). By extension, OE may not be assessed by a single operational definition because it takes on different forms for different types of organizations, environments in which organizations operate, and times. It is also vital to recognize that $\mathrm{OE}$, or empowerment at any level, is dynamic and changes over time. Operational definitions of $\mathrm{OE}$ for a newly formed child welfare agency located in the Northeastern United States in the 1980s may be very different from those for an established community organizing initiative located in the Midwest today. Nevertheless, one might expect each operationalization to capture intraorganizational, interorganizational, and extraorganizational qualities of $\mathrm{OE}$ appropriate to that context (e.g., geographic region, era, 
organizational type, and stage of organizational development).

A specific example of intraorganizational empowerment for a child welfare agency might include shared decision-making and teamwork among case workers and supervisors. Interorganizational empowerment might include agency collaboration with other social service organizations (e.g., housing, job readiness, etc.) to provide services to hard-to-reach populations. Extraorganizational empowerment for a child welfare agency might involve efforts to enact legislation that holds landlords more accountable for hazardous physical conditions threatening child safety. In another example, intraorganizational empowerment for a community organizing initiative might include frequent meetings in members' homes to discuss experiences and identify key community issues. Interorganizational empowerment might include a formalized linkage agreement with a community college to share facilities and expertise for a work-readiness program. Extraorganizational empowerment might include efforts to change bank policies that have historically discouraged economic and housing development in a low-income neighborhood. Notably, the nomological network for $\mathrm{OE}$ indicates that although concrete operations may be context specific, data would need to be captured on variables representing all three components to provide a complete picture of an empowered organization.

\section{Distinctions From Related Constructs}

Distinguishing OE from other related constructs will help to more clearly describe its nomological network. Social capital and collective efficacy are particularly relevant because they include features conceptualized at levels of analysis beyond the individual and share certain underlying principles with OE. Social capital, collective efficacy, and OE are similar in that they represent theoretical constructs considered to be protective factors that help moderate the deleterious effects of socioenvironmental risk (e.g., economic hardship, racism, violence, disinvestment in neighborhoods) on health and mental health outcomes. Such protective factors are fundamentally related, but are distinct constructs as well.

Social capital has been defined as the features of social organization (i.e., civic participation, norms of reciprocity, and trust in others) that facilitate cooperation and coordination for mutual benefit
(Coleman, 1988; Putnam, 1995). Social capital has primarily been operationalized as relationships between neighbors that may develop from their involvement in voluntary organizations such as soccer leagues and parent-teacher associations (Kawachi, Kennedy, Lochner, \& Prothrow-Stith, 1997). OE, conversely, focuses on transactions within and between organizations as well as between organizations and the larger systems that affect them. Thus, OE is a more inclusive construct involving multiple dimensions that consider factors beyond individuals and their relationships. OE processes may, nevertheless, help develop social capital.

Collective efficacy has been defined as social capital among neighbors combined with their willingness to intervene on behalf of the common good (Sampson, Raudenbush, \& Earls, 1997). This construct is more similar to OE than social capital because it integrates the idea of citizen involvement in organized efforts to exert influence in the community. Collective efficacy, however, is largely conceptualized as an individual-level construct that does not involve organizational characteristics. Rather, it is essentially an aggregate of individual willingness and intention to act and does not typically include actions taken, characteristics of the organized activity where the action may take place, or analysis of the organizational context in which the efficacy may have developed. OE, on the other hand, explicitly attends to features of collective action, while also incorporating ideas from multiple perspectives such as resource mobilization theory. Resource mobilization, for example, is a vital construct for $\mathrm{OE}$ as it is represented across all three components, but it has not been linked to either social capital or collective efficacy. Collective efficacy may be a bridging construct, however, between individual (psychological) empowerment and OE because it links individual outcomes (willingness and intention to intervene) with group processes (mutual trust and cohesion). As variables facilitating cooperation and joint action, both social capital and collective efficacy are constructs that may be relevant to intraorganizational, interorganizational, or extraorganizational empowerment.

Organizational development and community organization may also be distinguished from OE. Organizational development refers to the implementation of planned activities designed to improve the processes, climate, and effectiveness of organizations (Resnick \& Meneffe, 1993; Shinn \& Perkins, 2000). It usually involves consultants who try to help clients 
improve their organizations by applying knowledge from a variety of disciplines and theories. Community organization also refers to the implementation of intentional activities to bring about change, although its emphasis is on relationship building and joint action that improves a community's quality of life (Berkowitz, 2000). Although organizational development, community organization, and OE are similarly rooted in a democratic philosophy that recognizes the inherent dignity of the individual and the right of people to exercise selfdetermination (Alinsky, 1971; French \& Bell, 1984; Zippay, 1995), OE differs because it represents a theoretical construct whereas organizational development and community organization involve practice techniques that do not have a specific guiding theory (Piotrowski, Vodanovich, \& Armstrong, 2001). Many organizational development techniques could be directed, however, at enhancing the components of OE. Likewise, community organizing is a set of strategies that might be undertaken by an organization, and the extent of their success might be a measure of OE, particularly in relation to interorganizational and extraorganizational components of OE.

\section{CRITICAL ANALYSIS}

Our model of OE provides a first attempt to develop a conceptual foundation upon which to build an empirical literature on empowerment theory that extends beyond the individual level of analysis. Yet, this is only an initial effort to help guide research that can refine (or replace) our model. We have presented the three components of $\mathrm{OE}$ as distinct, but they are, of course, interrelated. We explicitly sought, however, to differentiate components and their features so that the distinctions could be presented more clearly. This approach parallels that of other researchers (e.g., Gardner, 1983) who described theories of multiple intelligences. Different types of intelligence, such as linguistic and interpersonal, are undoubtedly related to each other, although discussing them as if they were distinct is useful to understand the many complex components of each one individually. Similarly, our description of the intraorganizational, interorganizational, and extraorganizational components of $\mathrm{OE}$ recognizes the interrelationships across components. It is possible, for example, that organizational viability cuts across all three of the OE compo- nents even though we suggest it is part of the intraorganizational component. We suggest this is a core construct of the intraorganizational component, but recognize that it may also be a critical aspect of an organization's ability, for instance, to develop linkages with other organizations (interorganizational component) or affect policy (extraorganizational). Thus, the model we have presented should be considered a template to guide research on OE.

We also do not describe explicitly how our model integrates with empowerment at other levels of analysis. Although we included organizational characteristics of empowering organizations, we do not discuss connections between empowered individuals and OE. Similarly, we do not show how the model may be related to community empowerment even though we discuss how OE may be related to community change. The connections across levels of analysis, however, are vital for understanding empowerment theory more generally.

Our model of OE also needs further development to explain its implications for cross-component links between processes and outcomes. Implicit in our model is the notion that processes within any OE component may have effects on outcomes of any other component. Intraorganizational processes, for instance, may have effects on outcomes within interorganizational and extraorganizational components. Incentive management efforts combined with extensive subgroup linkages could produce more active organizational members with the knowledge and competencies needed to span organizational boundaries and create new community programs. Likewise, interorganizational processes may lead to outcomes within intraorganizational and extraorganizational components, whereas extraorganizational processes may have effects on outcomes within intraorganizational and interorganizational components. Participating in alliance-building activities with other organizations could provide members with experiences that help them identify new sources of funding or more effectively deploy organizational resources in the community. In addition, implementing a community action could serve to uniquely situate an organization to receive grant funding addressing a particular issue as well as stimulate the formation of new organizational settings and roles for members to occupy. The potential for organizational processes to influence outcomes across components is important to recognize as the $\mathrm{OE}$ framework is further developed. 


\section{CONCLUSION}

Studies on organizational-level attributes that define OE are necessary to advance empowerment research beyond its current individual bias. We offer a framework to guide both research and practice. Studies focusing on OE could lead to interventions that increase the capacity of organizations to achieve goals and improve quality of life in communities. Researchers have noted that efforts to build the capacity of organizations to gain the resources and power needed to create social change are necessary (Gerschick, 1989; Gutiérrez, et al. 1995; Itzhaky \& York, 2002; Sherman \& Wenocur, 1983; Zimmerman, 2000).

Empirical research is needed to further develop and test OE. One direction for future studies is the clarification of organizational characteristics that define OE. Narrative analysis (Riessman, 1993) may be a useful technique in this endeavor. Rappaport (1995) pointed out the utility of employing a narrative approach in empowerment studies, especially as a way to understand organizational characteristics of settings. Descriptive studies using this approach in a variety of contexts may be useful to further clarify qualities of OE. Another direction for future studies is to test relationships between the characteristics of OE we have presented and goal achievement among representative samples of organizations. The validity of the model could be examined by determining whether higher scores on variables representing $\mathrm{OE}$ outcomes were associated with higher levels of goal achievement. Research questions could also be tailored to examine variables that may moderate the effect of $\mathrm{OE}$ on goal achievement. The age of an organization, for instance, may be hypothesized as a potential moderator, although the nature of its effect may vary depending on social, political, and other environmental circumstances. A third direction for future research might be to identify dimensions of community structure and functioning (e.g., the availability of resources in a community to support a particular organizational mission or the existence of policies in a community that facilitate citizen participation) that may enhance or inhibit OE. Finally, the model of OE presented can be used to evaluate efforts to enhance communitybased grassroots organizations' capacity to become effective change agents, as well as the effectiveness of more traditional or formal organizations in achieving these same types of goals. We hope our model of OE helps set a course for programmatic research to further develop empowerment theory.

\section{ACKNOWLEDGMENTS}

This research was supported by grants from the Centers for Disease Control and Prevention to the Iowa Prevention Research Center (Grant Number: U48/CCU720075) and the Prevention Research Center of Michigan (Grant Number: U48/CCU515575). We gratefully acknowledge the reviewers for their very detailed and helpful comments, which helped our thinking and articulation of ideas.

\section{REFERENCES}

Alderfer, C. (1998). Understanding embedded intergroup relations: A comment on Yammarino and Jung. Journal of Applied Behavioral Science, 34, 68-75.

Alinsky, S. (1971). Rules for radicals. New York: Vintage.

Alter, C., \& Hage, J. (1993). Organizations working together (Vol. 191). Sage Library of Social Research. Newbury Park, CA.

Barker, R. G. (1960). Ecology and motivation. Nebraska Symposium on Motivation, 8, 1-44.

Barker, R. G., \& Gump, P. V. (1964). Big school, small school: High school size and student behavior. Stanford, CA: Stanford University Press.

Bartle, E. E., Couchonnal, G., Canda, E. R., \& Staker, M. D. (2002). Empowerment as a dynamically developing concept for practice: Lessons learned from organizational ethnography. Social Work, 47, 32-43.

Baum, J. A. C., \& Oliver, C. (1991). Institutional linkages and organizational mortality. Administrative Science Quarterly, 36, 187-218.

Bentley, K. J. (2000). Empowering our own: Peer leadership training for a drop-in center. Psychiatric Rehabilitation Journal, 24, 174-178.

Berger, P. L., \& Neuhaus, R. J. (1977). To empower people: The role of mediating structures in public policy. Washington, DC: American Enterprise Institute for Public Policy Research.

Berkowitz, B. (2000). Community and neighborhood organization. In J. Rappaport \& E. Seidman (Eds.), Handbook of community psychology (pp. 331-357). New York: Plenum.

Bonal, X. (2000). Interest groups and the state in contemporary Spanish education policy. Journal of Education Policy, 15, 201-216.

Bond, M., \& Keys, C. B. (1993). Empowerment, diversity, and collaboration: Promoting synergy on community boards. American Journal of Community Psychology, 21, 37-58.

Boyd, N. M., \& Angelique, H. (2002). Rekindling the discourse: Organization studies in community psychology. Journal of Community Psychology, 30, 325-348.

Braithwaite, R. L., \& Lythcott, N. (1989). Community empowerment as a strategy for health promotion for Black and other minority populations. Journal of the American Medical Association, 261, 283.

Breslow, L. (1992). Empowerment, not outreach: Serving the health promotion needs of the inner city. American Journal of Health Promotion, 7, 7-8.

Burstein, P. (1999). Social movements and public policy. In M. Giugni, D. McAdam, \& C. Tilly (Eds.), How social movements matter (pp. 3-21). Minneapolis, MN: Minnesota Press. 
Checkoway, B. (1982). The empire strikes back: More lessons for health care consumers. Journal of Health Politics, Policy, and Law, 7, 111-125.

Checkoway, B., \& Doyle, M. (1980). Community organizing lessons for health care consumers. Journal of Health Politics, Policy, and Law, 5, 213-227.

Cherniss, C., \& Deegan, G. (2000). The creation of alternative settings. In J. Rappaport \& E. Seidman (Eds.), Handbook of community psychology (pp. 359-378). New York: Kluwer Academic/Plenum Publishers.

Coleman, J. S. (1988). Social capital in the creation of human capital. American Journal of Sociology, 94, S95-S120.

Cox, C. B. (2002). Empowering African American custodial grandparents. Social Work, 47, 45-54.

Cronbach, L. J., \& Meehl, P. E. (1955). Construct validity in psychological tests. Psychological Bulletin, 52, 281-302.

Damania, R., \& Fredriksson, P. G. (2000). On the formation of industry lobby groups. Journal of Economic Behavior and Organization, 41, 315-335.

Darley, J. M., \& Gilbert, D. T. (1985). Social psychological aspects of environmental psychology. In G. Lindzey \& E. Aronson (Eds.), Handbook of social psychology (3rd ed., pp. 949-991). New York: Random House.

Donaldson, L. (1995). American anti-management theories of organization: A critique of paradigm proliferation. Cambridge, England: Cambridge University Press.

Fawcett, S. B., Paine-Andrews, A., Francisco, V., Schulz, J., Richter, K., Lewis, R., et al. (1995). Using empowerment theory in collaborative partnerships for community health and development. American Journal of Community Psychology, 23, 677-698.

Foster-Fishman, P. G., \& Keys, C. B. (1997). The person/environment dynamics of employee empowerment: An organizational culture analysis. American Journal of Community Psychology, 25, 345-369.

Foster-Fishman, P. G., Salem, D. A., Allen, N. A., \& Fahrbach, K. (2001). Facilitating interorganizational collaboration: The contributions of interorganizational alliances. American Journal of Community Psychology, 29, 875905.

Foster-Fishman, P. G., Salem, D. A., Chibnall, S., Legler, R., \& Yapchai, C. (1998). Empirical support for the critical assumptions of empowerment theory. American Journal of Community Psychology, 26, 507-536.

French, W. L., \& Bell, C. H. (1984). Organizational development: Behavioral science interventions for organization improvement. Englewood Cliffs, NJ: Prentice-Hall.

Frymier, A. B., Shulman, G. M., \& Houser, M. (1996). The development of a learner empowerment measure. Communication Education, 45, 181-199.

Gardner, H. (1983). Frames of mind: A theory of multiple intelligences. London: Fontana Press.

Gaventa, J. (1980). Power and powerlessness: Quiescence and rebellion in an Appalachian valley. Urbana, IL: University of Illinois Press.

Gerschick, T., Israel, B., \& Checkoway, B. (1989). Means of empowerment in individuals, organizations, and communities: Report from a retrieval conference. University of Michigan, Center for research on Social Organizations, Ann Arbor, MI.

Gerschick, T. J., Israel, B. A., \& Checkoway, B. N. (1990). Means of empowerment in individuals, organizations, and communities. Ann Arbor, MI: University of Michigan, Program on Conflict Management Alternatives.

Gray, B. (1985). Conditions facilitating interorganizational collaboration. Human Relations, 38, 911-936.

Gruber, J., \& Trickett, E. J. (1987). Can we empower others? The paradox of empowerment in the governing of an alternative public school. American Journal of Community Psychology, $15,353-371$.
Gulati, R., \& Gargiulo, M. (1999). Where do interorganizational networks come from? American Journal of Sociology, 104, 1439-1493.

Gutiérrez, L. M. (1995). Understanding the empowerment process: Does consciousness make a difference? Social Work Research, 19, 229-237.

Gutiérrez, L. M., GlenMaye, L., \& DeLois, K. (1995). The organizational context of empowerment practice: Implications for social work administration. Social Work, 40, 249258.

Hardiman, E. R., \& Segal, S. P. (2003). Community membership and social networks in mental health self-help agencies. Psychiatric Rehabilitation Journal, 27, 25-33.

Itzhaky, H., \& York, A. S. (2002). Showing results in community organization. Social Work, 47, 125-131.

Jacoby, A. P., \& Babchuk, N. (1963). Instrumental and expressive voluntary associations. Sociology and Social Research, 47, $461-471$.

Katz, D. N., \& Kahn, R. L. (1978). The social psychology of organizations. New York: Wiley.

Kawachi, I., Kennedy, B. P., Lochner, K., \& Prothrow-Stith, D. (1997). Social capital, income equality, and mortality. American Journal of Public Health, 87, 14911497.

Kelly, J. G. (1966). Ecological constraints on mental health services. American Psychologist, 21, 535-539.

Kelly, J. G., Ryan, A. M., Altman, B. E., \& Stelzner, S. P. (2000). Understanding and changing social systems: An ecological view. In J. Rappaport \& E. Seidman (Eds.), Handbook of community psychology (pp. 133-159). New York: Kluwer Academic/Plenum Publishers.

Klein, K. J., Ralls, R. S., Smith-Major, V., \& Douglass, C. (2000). Power and participation in the workplace: Implications for empowerment theory, research, and practice. In J. Rappaport \& E. Seidman (Eds.), Handbook of community psychology (pp. 273-295). New York: Kluwer Academic/Plenum Publishers.

Le Bosse, Y., Lavallee, M., Lacerte, D., Dube, N., Nadeau, J., Porcher, E., et al. (1999). Is community participation empirical evidence for psychological empowerment?: Distinction between passive and active participation. Journal of Social Work and Social Sciences Review, 8, 59-82.

Maton, K. I. (1988). Social support, organizational characteristics, psychological well-being, and group appraisal in three self-help group populations. American Journal of Community Psychology, 16, 53-77.

Maton, K. I., \& Salem, D. A. (1995). Organizational characteristics of empowering community settings: A multiple case study approach. American Journal of Community Psychology, 23, 631-656.

Matthews, R. A., Diaz, M. W., \& Cole, S. G. (2003). The organizational empowerment scale. Personnel Review, 32(3), 297318.

McCarthy, J. D., \& Zald, M. N. (1973). The trend of social movements in America: Professionalization and resource mobilization. Morristown, NJ: General Learning Press.

McCarthy, J. D., \& Zald, M. N. (1977). Resource mobilization and social movements: A partial theory. American Journal of Sociology, 82, 1212-1241.

Minkler, M., Thompson, M., Bell, J., \& Rose, K. (2001). Contributions of community involvement to organizational-level empowerment: The federal healthy start experience. Health Education and Behavior, 28, 783-807.

Orians, C., Liebow, E., \& Branch, K. (1995). Community-based organizations and HIV prevention among Seattle's inner-city teens. Urban Anthropology, 24, 36-58.

Palmer, D. P. (1983). Broken ties: Interlocking directorates and intercorporate coordination. Administrative Science Quarterly, $28,40-55$. 
Perkins, D. D., Brown, B. B., \& Taylor, R. B. (1996). The ecology of empowerment: Predicting participation in community organizations. Journal of Social Issues, 52, 85-110.

Perkins, D. D., \& Zimmerman, M. A. (1995). Empowerment theory, research, and application: An introduction to a special issue. American Journal of Community Psychology, 23, 569579 .

Peterson, N. A., \& Hughey, J. (2002). Tailoring organizational characteristics for empowerment: Accommodating individual economic resources. Journal of Community Practice, 10, 4159.

Peterson, N. A., \& Reid, R. J. (2003). Paths to empowerment in an urban community: Sense of community and citizen participation in substance abuse prevention activities. Journal of Community Psychology, 31, 25-38.

Peterson, N. A., \& Speer, P. W. (2000). Linking organizational characteristics to psychological empowerment: Contextual issues in empowerment theory. Administration in Social Work, $24,39-58$.

Pfeffer, J. (1997). New directions for organizational theory: Prospects and problems. New York: Oxford University Press.

Pinderhughes, E. (1989). Understanding race, ethnicity, and power: The key to efficacy in clinical practice. New York: Free Press.

Piotrowski, C., Vodanovich, S. J., \& Armstrong, T. (2001). Theoretical orientations of organizational development practitioners. Social Behavior and Personality, 29, 307312.

Prestby, J. E., Wandersman, A., Florin, P., Rich, R., \& Chavis, D. (1990). Benefits, costs, incentive management and participation in voluntary organizations: A means to understanding and promoting empowerment. American Journal of Community Psychology, 18, 117-149.

Putnam, R. D. (1995). Bowling alone: America's declining social capital. Journal of Democracy, 6, 65-76.

Rappaport, J. (1981). In praise of paradox: A social policy of empowerment over prevention. American Journal of Community Psychology, 9, 1-25.

Rappaport, J. (1984). Studies in empowerment: Introduction to the issue. In J. Rappaport, C. Swift, \& R. Hess (Eds.), Studies in empowerment: Steps toward understanding and action (pp. 1-7). New York: Haworth Press.

Rappaport, J. (1987). Terms of empowerment/exemplars of prevention: Toward a theory for community psychology. American Journal of Community Psychology, 15, 121148.

Rappaport, J. (1993). Narrative studies, personal stories, and identity transformation in the mutual help context. Journal of Applied Behavioral Science, 29, 239-256.

Rappaport, J. (1995). Empowerment meets narrative: Listening to stories and creating settings. American Journal of Community Psychology, 23, 795-808.

Resnick, H., \& Menefee, D. (1993). A comparative analysis of organization development and social work, with suggestions for what organization development can do for social work. Journal of Applied Behavioral Science, 29, 432445.

Riessman, C. K. (1993). Narrative analysis. In Judith L. Hunter (Ed.), Qualitative research methods (whole no. 30). Newbury Park, CA: Sage.

Riger, S. (1984). Vehicles for empowerment: The case of feminist movement organizations. Studies in Empowerment, 3, 99-117.

Riger, S. (1993). What's wrong with empowerment. American Journal of Community Psychology, 21, 279-292.

Rissel, C. (1994). Empowerment: The holy grail of health promotion? Health Promotion International, 9, 39-47.

Robertson, P. J. (1995). Involvement in boundary spanning activity: Mitigating the relationship between work setting and behavior. Journal of Public Administration Research and Theory, 5, 73-100.
Rose, A. M. (1954). Theory and the method in the social sciences. Minneapolis, MN: University of Minneapolis Press.

Sampson, E. E. (1977). Psychology and the American ideal. Journal of Personality and Social Psychology, 35, 767-782.

Sampson, R. J., Raudenbush, S. W., \& Earls, F. (1997). Neighborhoods and violent crime: A multilevel study of collective efficacy. Science, 277, 918-924.

Sarason, S. B. (1972). The creation of settings and the future of societies. San Francisco: Jossey-Bass.

Scott, W. R. (1998). Organizations: Rational, natural, and open systems. Upper Saddle River, NJ: Prentice-Hall.

Segal, S. P., Silverman, C., \& Temkin, T. (1995). Measuring empowerment in client-run self-help agencies. Community Mental Health Journal, 31, 215-227.

Sherman, W., \& Wenocur, S. (1983). Empowering public welfare workers through mutual support. Social Work, 28, 275279.

Shinn, M., \& Perkins, D. N. T. (2000). Contributions from organizational psychology. In J. Rappaport \& E. Seidman (Eds.), Handbook of community psychology (pp. 615-642). New York: Kluwer Academic/Plenum Publishers.

Snow, D. A., Zurcher, L. A., \& Elkind-Olson, S. (1980). Social networks and social movements. American Sociological Review, $45,787-801$.

Solomon, B. (1976). Black empowerment: Social work in oppressed communities. New York: Columbia University Press.

Specht, H., \& Courtney, M. E. (1994). Unfaithful angels: How social work has abandoned its mission. New York: Free Press.

Speer, P. W. (2000). Intrapersonal and interactional empowerment: Implications for theory. Journal of Community Psychology, 28, 51-61.

Speer, P. W., \& Hughey, J. (1995). Community organizing: An ecological route to empowerment and power. American Journal of Community Psychology, 23, 729-748.

Speer, P. W., \& Hughey, J. (1996). Mechanisms of empowerment: Psychological processes for members of power-based community organizations. Journal of Community and Applied Social Psychology, 6, 177-187.

Speer, P. W., Hughey, J., Gensheimer, L. K., \& Adams-Leavitt, W. (1995). Organizing for power: A comparative case study. Journal of Community Psychology, 23, 57-73.

Speer, P. W., \& Peterson, N. A. (2000). Psychometric properties of an empowerment scale: Testing cognitive, emotional and behavioral domains. Social Work Research, 24, 2, 109-118.

Spreitzer, G. M. (1995). An empirical test of a comprehensive model of intrapersonal empowerment in the workplace. American Journal of Community Psychology, 23, 601629.

Stevenson, W. B., \& Greenberg, D. (2000). Agency and social networks: Strategies of action in a social structure of position, opposition, and opportunity. Administrative Science Quarterly, 45, 651-678.

Swift, C., \& Levin, G. (1987). Empowerment: An emerging mental health technology. Journal of Primary Prevention, 8, 7192.

Trist, E. (1986). Quality of working life and community development: Some reflections on the Jamestown experience. Journal of Applied Behavioral Science, 22, 223-237.

Wicker, A. W. (1987). Behavior settings reconsidered: Temporal stages, resources, internal dynamics, context. In D. Stokols \& A. Altman (Eds.), Handbook of environmental psychology (Vol. 1, pp. 613-653). New York: Wiley.

Zimmerman, M. A. (1995). Psychological empowerment: Issues and illustrations. American Journal of Community Psychology, 23, 581-600.

Zimmerman, M. A. (2000). Empowerment theory: Psychological, organizational, and community levels of analysis. In 
J. Rappaport \& E. Seidman (Eds.), Handbook of community psychology (pp. 43-63). New York: Plenum.

Zimmerman, M. A., Reischl, T. M., Seidman, E., Rappaport, J., Torro, P. A., \& Salem, D. A. (1991). Expansion strategies of a mutual help organization. American Journal of Community

Psychology, 19, 251-278.
Zimmerman, M. A., \& Zahniser, J. H. (1991). Refinements of sphere-specific measures of perceived control: Development of a sociopolitical control scale. Journal of Community Psychology, 19, 189-204.

Zippay, A. (1995). The politics of empowerment. Social Work, 40, 263-267. 